\title{
Article \\ Schizophrenia and hospital admissions for cardiovascular events in a large population. The APNA Study.
}

\author{
Sara Guillen-Aguinaga 1,2, Antonio Brugos-Larumbe ${ }^{2}$, Laura Guillen-Aguinaga ${ }^{3}$, Felipe Ortuño 4,5, Francisco Gui- \\ llen-Grima ${ }^{2,5,6,7 *}$, Luis Forga ${ }^{5,8}$ and Ines Aguinaga-Ontoso ${ }^{2}$.
}

\author{
Navarra Health Service. Pamplona, Navarra. Spain; sguillen.4@alumni.unav.es \\ 2 Dept. Health Sciences. Public University of Navarra (UPNA). Pamplona, Navarra, Spain; \\ ablm649@gmail.com, frguillen@unav.es, ines.aguinaga@unavarra.es \\ 3 Clinica Universidad de Navarra. Pamplona, Navarra. Spain; lguillen@unav.es \\ 4 Dept. of Psychiatry. Clinica Universidad de Navarra. Pamplona, Navarra. Spain;ffortunos@unav.es \\ 5 Navarra Institute of Health Research (IdiSNA), Pamplona, Navarra, Spain. \\ 6 Dept. of Preventive Medicine. Clinica Universidad de Navarra, Pamplona, Navarra, Spain. \\ 7 CIBER-OBN, Instituto de Salud Carlos III, Madrid, Spain. \\ 8 Department of Endocrinology, Hospital of Navarra, C/ Irunlarrea s/n, Pamplona 31008, Spain. \\ 1luis.forga.llenas@navarra.es \\ * Correspondence: Correspondence: frguillen@unav.es; Tel.: (+34-948-296384)
}

\begin{abstract}
Background: Patients with schizophrenia have higher mortality, with cardiovascular diseases being the first cause of mortality. This study aims to estimate the excess risk of hospital admission for cardiovascular events in schizophrenic patients, adjusting for comorbidity and risk factors. (2) Methods: The APNA study is a dynamic prospective cohort of all residents in Navarra, Spain. 505889 people over 18 years were followed during 5 years. The endpoint was hospital admissions for a cardiovascular event. Direct Acyclic Graphs (DAG) and Cox regression were used. (3) Results: Schizophrenic patients had an HR 1.414 (1.031-1.938) of hospital admission for a cardiovascular event after adjusting for age, sex, hypertension, type 2 diabetes, dyslipidemia, smoking, low income, obesity, Charlson Index, antecedents of cardiovascular disease, and smoking. (4) Conclusions: Patients with schizophrenia have a higher risk of hospital admission for cardiovascular events than persons with the same risk factors without schizophrenia. Primary care nursing interventions should be implemented to monitor these patients and reduce cardiovascular risk factors.
\end{abstract}

Keywords: Cardiovascular; Schizophrenia; Prospective Cohort; hospital admissions

\section{Introduction}

Schizophrenia is a severe mental illness associated with elevated cardiovascular disease risk. Patients with schizophrenia have higher comorbidity (notably higher risk of cardiovascular diseases) and higher mortality [1]. A meta-analysis showed that mortality rates were 2.5 times higher in patients with schizophrenia. Suicides were higher in patients with schizophrenia. In addition, mortality rates from the major causes of death were higher in patients with schizophrenia than in the general population [2]. Cardiovascular disease is the first leading cause of mortality in patients with schizophrenia, followed by cancer and suicide [3,4]. Likewise, the onset of the first episode of vascular diseases is lower [5]. Moreover, after an infarction, revascularization rates are lower in patients with schizophrenia [6]. A cohort study conducted in Singapore showed that patients with schizophrenia with physical comorbidity (diabetes, hypertension, coronary heart disease, and cancer) had an increased mortality risk [7].

This research aims to study whether patients with schizophrenia have an increased risk of hospital admissions for cardiovascular diseases independently of their comorbidity. 


\section{Materials and Methods}

The "Navarre primary health care system cohort" (APNA study) is a dynamical multipurpose prospective cohort. It started in 2004 in the autonomous community of Navarre (northern Spain). Details on the cohort design are available elsewhere [8-11].

Briefly, the population of Navarra primary health care data has been recorded since 2004 [8]. In this study, we selected people over 18 years old. The follow-up in this study was from 2012 to 2016 . The average population in the period was 505889 people.

\subsection{Study variables:}

We collected age, sex, date of hospital admissions for cardiovascular events, and low-income status. Income levels were obtained from the TSI used for the pharmaceutical co-payment. Low income was considered TSI 001, which includes people with non-contributory pensions (5150€/year), Social Integration Income (7640€/year), or unemployed people without unemployment benefits [12]. We obtained the variable admission for a cardiovascular event from hospital records.

Clinical variables: the following variables were used: weight (kilograms), height (meters), Body Mass Index (BMI) (weight/height ${ }^{2}$ ), systolic and diastolic BP (mmHg), and smoking during the follow-up period. Patients with BMI $>30$ were classified as obese. We recorded diagnoses of type 2 diabetes, hypertension, and dyslipidemia. From hospitals records, we extracted the history of hospital admission for cardiovascular events. Comorbidity was computed with the Charlson Index [13] and the Comorbidity Index [14].

Patients with schizophrenia diagnosis using ICD-10 by a psychiatrist from Navarre health service were identified in the database. A person who had not been diagnosed with schizophrenia was considered free from the illness.

\subsection{Statistical Analysis:}

We use Directed Acyclic Graphic (DAG) (Figure 1) to study the relationship of schizophrenia with hospital admissions for cardiovascular events and potential confounding factors. In Figure 2, we show the causal path between schizophrenia and hospital admissions for cardiovascular events.

In the descriptive analysis, we present the data of categorical variables as proportion with confidence intervals. In the quantitative variables, we present mean and standard deviation or median and interquartile deviation when adequate. Comparisons among categorical variables were calculated with the Chi-square test. Comparisons between groups in quantitative variables were performed with Student's $t$. When quantitative variables were scales or did not have a normal distribution, we computed a non-parametric test Kruskal-Wallis. Cox regression was used to estimate the excess risk of hospital admissionS for cardiovascular events associated with schizophrenia. There was a high correlation between Charlson and the comorbidity Index. Because of that, we used the Charlson index in the analysis. Data were analyzed with IBM SPSS and Openepi [15]. 


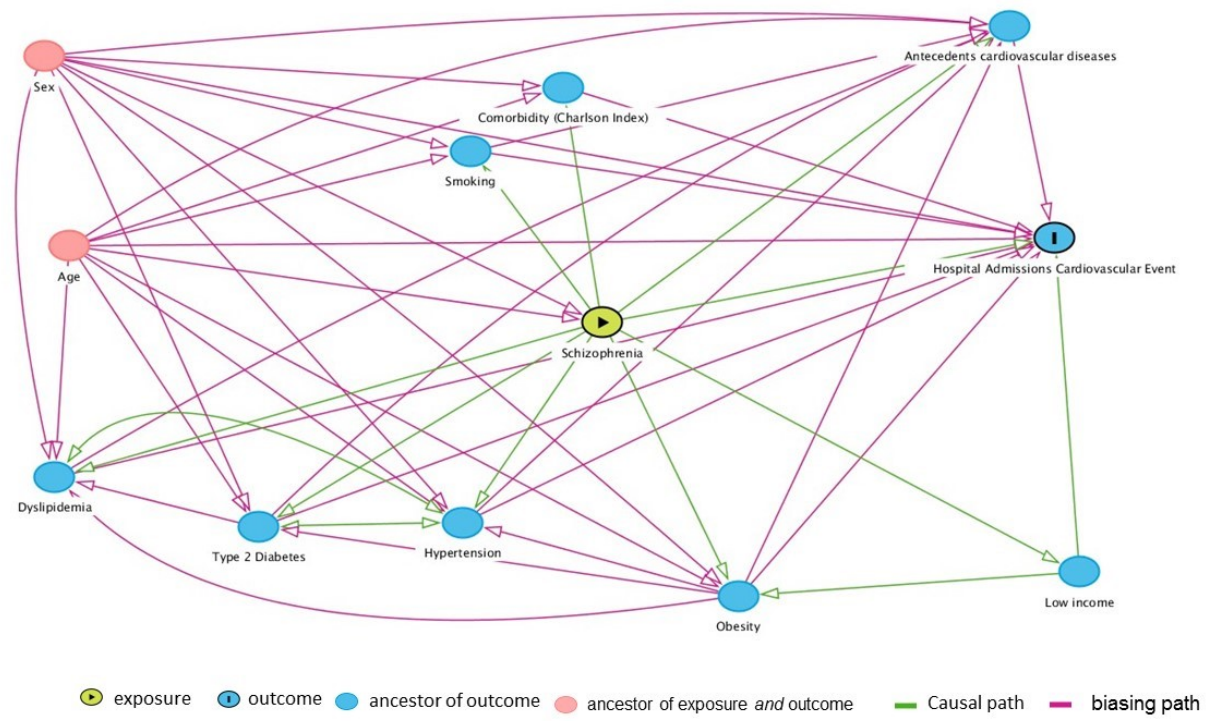

Figure 1. Directed Acyclic Graphic (DAG) of schizophrenia and Hospital Admissions for Cardiovascular events.

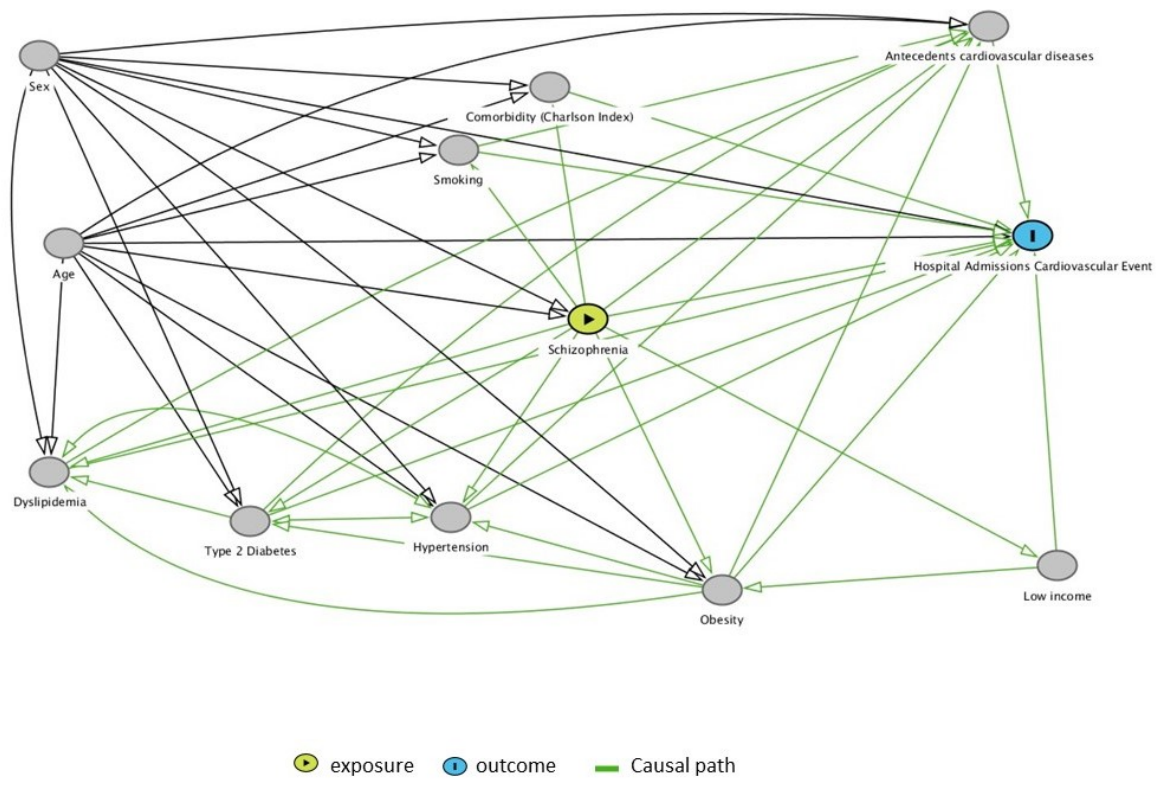

Figure 2. DAG Showing the causal paths from schizophrenia to hospital admission for cardiovascular events.

\section{Results}

The analysis included 505889 people with 2700505 follow-up years. During the following period, there were 2495 vascular events. The incidence of cardiovascular events was 355.5 per 100000 person-years in patients with schizophrenia versus 91.1 per 100000 person-years in persons without schizophrenia with a Rate Ratio of $3.903(95 \%$ CI 2.924-5.208). The proportion of males was higher in persons with schizophrenia, $59.8 \%$ vs. $49.2 \%$. (Table 1). The proportion of persons with low income was four times higher in patients with schizophrenia, $12.9 \%$ vs. 3.8\%. Obesity, Diabetes, and Smoking were higher in patients with schizophrenia, while the prevalence of hypertension was lower 
than in the person without the disease. Dyslipidemia, comorbidity, and Charlson Index were similar in both groups.

Table 1. Patients' characteristics.

\begin{tabular}{|c|c|c|c|}
\hline & $\begin{array}{c}\text { Schizophrenia } \\
\mathbf{N}=\mathbf{2 4 9 5}\end{array}$ & $\begin{array}{c}\text { No Schizophrenia } \\
\mathrm{N}=503394\end{array}$ & \\
\hline Variables & $\begin{array}{c}\% \\
\text { Mean (SD) }\end{array}$ & $\begin{array}{c}\% \\
\text { Mean (SD) }\end{array}$ & $\mathrm{p}$ \\
\hline Age(years) & 49.7 (15.7) & $50.0(18.0)$ & $0.342^{+}$ \\
\hline Male & $59.8 \%$ & $49.2 \%$ & $<0.001 \ddagger$ \\
\hline Low Income & $12.9 \%$ & $3.8 \%$ & $<0.001^{\ddagger}$ \\
\hline Charlson Index & $1.3(1.8)$ & $1.3(1.7)$ & $0.677^{*}$ \\
\hline Comorbidity Index & $1.2(1.5)$ & $1.2(1.7)$ & $0.512^{*}$ \\
\hline (Obesity) BMI > 30 & $41.5 \%$ & $25.9 \%$ & $<0.001^{\ddagger}$ \\
\hline BMI & $29.4(6.3)$ & $27.2(5.2)$ & $<0.001^{+}$ \\
\hline CV Antecedents & $8.9 \%$ & $9.5 \%$ & $0.243^{\ddagger}$ \\
\hline Diabetes & $7.8 \%$ & $5.4 \%$ & $<0.001^{\ddagger}$ \\
\hline Hypertension & $12.5 \%$ & $15.1 \%$ & $0.001^{\ddagger}$ \\
\hline Dyslipidemia & $27.1 \%$ & $25.9 \%$ & $0.221^{\ddagger}$ \\
\hline Smoking & $19.8 \%$ & $9.1 \%$ & $<0.001 \ddagger$ \\
\hline
\end{tabular}

+ Student's T ‡ Chi-square *Kruskal-Wallis.

On the Cox model adjusted for age and sex, patients with schizophrenia compared with people without schizophrenia had an HR of 1,348 (1,009-1,801) for a cardiovascular event hospital admission, $p=0,044$. In the final multivariate model that was adjusted for age, sex, Hypertension, Type 2 Diabetes, Dyslipidemia, Smoking, Low Income, Obesity, Charlson Index, antecedents of cardiovascular disease, and smoking patients with schizophrenia had an HR of (95\% CI) 1.414 (1.031-1.938), $\mathrm{p}=0.031$. (Table 2)

Table 2. Univariate and multivariate cox regression for hospital admission for cardiovascular events.

\begin{tabular}{|c|c|c|c|c|}
\hline & $\begin{array}{l}\text { Model Adjusted by age } \\
\text { and sex }\end{array}$ & & $\begin{array}{l}\text { del Adjusted by all varia- } \\
\text { bles in the model }\end{array}$ & \\
\hline Variables & HR $(95 \%$ CI) & p & HR $(95 \%$ CI) & p. \\
\hline Schizophrenia & $1.348(1.009-1.801)$ & 0.044 & $1.414(1.031-1.938)$ & 0.031 \\
\hline Hypertension & $1.221(1.165-1.280)$ & $<0.001$ & $1.131(1.076-1.189)$ & $<0.001$ \\
\hline Type 2 Diabetes & $2.099(1.995-2.208)$ & $<0.001$ & $1.327(1.252-1.406)$ & $<0.001$ \\
\hline Dyslipidemia & $1.333(1.276-1.393)$ & $<0.001$ & $1.083(1.034-1.136)$ & 0.001 \\
\hline $\begin{array}{c}\text { Antecedents of cardiovascular } \\
\text { disease }\end{array}$ & $7.860(7.474-8.265)$ & $<0.001$ & $5.475(5.152-5.817)$ & $<0.001$ \\
\hline Smoking & $1.477(1.370-1.591)$ & $<0.001$ & 1.089 (1.004-1.180) & 0.039 \\
\hline Low Income & $1.739(1.544-1.959)$ & $<0.001$ & $1.498(1.310-1.712)$ & $<0.001$ \\
\hline Obesity $(\mathrm{BMI}>30)$ & $1.285(1.224-1.350)$ & $<0.001$ & $1.152(1.095-1.209)$ & $<0.001$ \\
\hline Charlson & $1.444(1.430-1.459)$ & $<0.001$ & $1.123(1.104-1.143)$ & $<0.001$ \\
\hline Age & $1.077(1.076-1.079)$ & $<0.001$ & $1.031(1.028-1.034)$ & $<0.001$ \\
\hline Male & $2.465(2.355-2.580)$ & $<0.001$ & $1.902(1.809-2.001)$ & $<0.001$ \\
\hline
\end{tabular}

\section{Discussion}

In this study, the main limitation is that we only had access to hospital admissions. We did not have access to death certificates, so the incidence rate is probably underestimated and higher than the estimates presented. Another limitation is that we have not analyzed the physical exercise of the patients since this is an item that is usually poorly recorded in the computerized medical records.

This study shows that people with schizophrenia have a higher probability of having a cardiovascular event after adjusting for sociodemographic factors, lifestyle, and comorbidity. Individuals with severe mental illness experience increased morbidity and 
mortality compared to the general population. Among the explanations could be a higher prevalence of hazardous health behaviors that are cardiovascular risk factors. (Smoking, addiction, poor diet, lack of exercise, obesity) [16]. Molecular and genetic mechanisms [17], such as an accelerated shortening of the telomeres, may also play a role [18].

It is also possible that there may be differences in the accessibility of health care, the detection of somatic diseases, their treatment, and the attitudes of health care professionals [19]. A Metanalysis found that patients with schizophrenia have less screening and lower-quality treatment [20]. Thus, a retrospective cohort study conducted in Ontario showed that patients with schizophrenia were less frequently treated with thrombolysis, had fewer diagnostic tests such as carotid imaging, and were less likely to be in rehabilitation and treated with anticoagulants antihypertensives, or lipid-lowering drugs at discharge [21].

The cardio-metabolic adverse effects of antipsychotics, including weight gain, may contribute to the development of metabolic syndrome [3,22, 23], which is associated with an increased risk of all-cause and cardiovascular disease mortality. Antipsychotic drugs may exacerbate atherosclerosis [24]. Dysregulation of coagulation and complement may occur in patients with schizophrenia under treatment [25].

Patients with schizophrenia with diabetes have a higher risk of mortality and cardiovascular disease than persons without schizophrenia with diabetes. [26] Although the mechanisms leading to increased morbidity from cardiovascular disease are not yet precise, clinicians, especially General Practitioners (GPs) dealing with patients with schizophrenia, should be aware that they have an increased likelihood of cardiovascular disease. In this research, we have adjusted for the factors that can influence the occurrence of events. The increased CV risk may be due to factors that have not been assessed for the degree of control of these risk factors, such as diabetes, hypertension, and dyslipidemia. Our investigation has adjusted for being diabetic or not, but not for being well or poorly controlled for diabetes. Future research should study the existence of differences in the control of cardiovascular risk factors.

Nurses' intervention programs have been shown to reduce cardiovascular risk factors in women with schizophrenia [27]. Clinical trials are currently underway to reduce cardiovascular risk in young patients with schizophrenia [28]. Nurses' health promotion programs should be carried out in patients with schizophrenia to reduce cardiovascular risk factors.

\section{Conclusions}

Schizophrenia patients have a higher risk of hospital admission for cardiovascular events than persons with the same risk factors without schizophrenia. Specialist physicians and general practitioners need to be aware of this increased cardiovascular risk in patients with schizophrenia and instruct nurses to monitor them and include them in their follow-up programs. Primary care nursing interventions should be implemented to monitor these patients and reduce cardiovascular risk factors.

\section{Supplementary Materials: None}

Author Contributions: Conceptualization, Sara Guillen-Aguinaga and Francisco Guillen-Grima; Data curation, Sara Guillen-Aguinaga and Antonio Brugos-Larumbe; Funding acquisition, Luis Forga; Methodology, Sara Guillen-Aguinaga, Antonio Brugos-Larumbe, Francisco Guillen-Grima and Ines Aguinaga-Ontoso; Supervision, Antonio Brugos-Larumbe, Felipe Ortuño and Ines Aguinaga-Ontoso; Visualization, Laura Guillen-Aguinaga and Francisco Guillen-Grima; Writing - original draft, Sara Guillen-Aguinaga, Laura Guillen-Aguinaga, Francisco Guillen-Grima and Ines Aguinaga-Ontoso; Writing - review \& editing, Sara Guillen-Aguinaga, Antonio Brugos-Larumbe, Laura Guillen-Aguinaga, Felipe Ortuño, Francisco Guillen-Grima, Luis Forga and Ines Aguinaga-Ontoso. All authors have read and agreed to the published version of the manuscript.

Funding: Menarini supported this study with an unconditional sponsored research grant. 
Institutional Review Board Statement: The APNA study received approvals from the Spanish Agency for Medicines and Health Products of the Ministry of Health, Social Services, and Equality under code ABL-MET-2013-01 on 9 December 2013 and from the Clinical Research Ethics Committee of the Government of Navarra. (CEIC) number 3/2014 on 26 March 2014 and number 83/2014 on 30 September 2014.

Informed Consent Statement: The database is an administrative database of Primary Health Care Clinical Records collected during routine procedures. All users of Primary Health Care Centers knew that their clinical records were registered. They had the right to the cancellation of their records.

Data Availability Statement: The datasets generated for this study are unavailable due to the data protection law.

\section{Acknowledgments: None.}

Conflicts of Interest: The authors declare no conflict of interest. The funders had no role in the study's design, in the collection, analyses, or interpretation of data, in the writing of the manuscript, or in the decision to publish the results.

\section{References}

1. Lavagnino, L.; Gurguis, C.; Lane, S. Risk Factors for Metabolic and Cardiovascular Disease in Inpatients with Severe Mental Illness. Psychiatry Res. 2021, 304, 114148. https://doi.org/10.1016/j.psychres.2021.114148.Author 1, A.; Author 2, B. Title of the chapter. In Book Title, 2nd ed.; Editor 1, A., Editor 2, B., Eds.; Publisher: Publisher Location, Country, 2007; Volume 3, pp. 154-196.

2. Saha, S.; Chant, D.; McGrath, J. A Systematic Review of Mortality in Schizophrenia: Is the Differential Mortality Gap Worsening over Time? Arch. Gen. Psychiatry 2007, 64 (10), 1123-1131. https://doi.org/10.1001/archpsyc.64.10.1123.

3. Azad, M. C.; Shoesmith, W. D.; Al Mamun, M.; Abdullah, A. F.; Naing, D. K. S.; Phanindranath, M.; Turin, T. C. Cardiovascular Diseases among Patients with Schizophrenia. Asian J. Psychiatr. 2016, 19, 28-36. https://doi.org/10.1016/j.ajp.2015.11.012.

4. Moreno-Küstner, B.; Guzman-Parra, J.; Pardo, Y.; Sanchidrián, Y.; Díaz-Ruiz, S.; Mayoral-Cleries, F. Excess Mortality in Patients with Schizophrenia Spectrum Disorders in Malaga (Spain): A Cohort Study. Epidemiol. Psychiatr. Sci. 2021, 30 , e11. https://doi.org/10.1017/S2045796020001146.

5. Marche, J.-C.; Bannay, A.; Baillot, S.; Dauriac-Le Masson, V.; Leveque, P.; Schmitt, C.; Laprévote, V.; Schwan, R.; Dobre, D. Prevalence of Severe Cardiovascular Disease in Patients with Schizophrenia. Encephale. 2021. https://doi.org/10.1016/j.encep.2021.02.008.

6. Fleetwood, K.; Wild, S. H.; Smith, D. J.; Mercer, S. W.; Licence, K.; Sudlow, C. L. M.; Jackson, C. A. Severe Mental Illness and Mortality and Coronary Revascularisation Following a Myocardial Infarction: A Retrospective Cohort Study. BMC Med. 2021, 19 (1), 67. https://doi.org/10.1186/s12916-021-01937-2.

7. Tan, X. W.; Lee, E. S.; Toh, M. P. H. S.; Lum, A. W. M.; Seah, D. E. J.; Leong, K. P.; Chan, C. Y. W.; Fung, D. S. S.; Tor, P. C. Comparison of Mental-Physical Comorbidity, Risk of Death and Mortality among Patients with Mental Disorders - A Retrospective Cohort Study. J. Psychiatr. Res. 2021, 142, 48-53. https://doi.org/10.1016/j.jpsychires.2021.07.039.

8. Brugos-Larumbe, A.; Aldaz-Herce, P.; Guillen-Grima, F.; Garjón-Parra, F. J.; Bartolomé-Resano, F. J.; Arizaleta-Beloqui, M. T.; Pérez-Ciordia, I.; Fernández-Navascués, A. M.; Lerena-Rivas, M. J.; Berjón-Reyero, J.; Jusué-Rípodas, L.; Aguinaga-Ontoso, I. Assessing Variability in Compliance with Recommendations given by the International Diabetes Federation (IDF) for Patients with Type 2 Diabetes in Primary Care Using Electronic Records. The APNA Study. Prim. Care Diabetes 2018, 12 (1), $34-44$. https://doi.org/10.1016/j.pcd.2017.06.008.

9. Martin-Rodriguez, E.; Guillen-Grima, F.; Aubá, E.; Martí, A.; Brugos-Larumbe, A. Relationship between Body Mass Index and Depression in Women: A 7-Year Prospective Cohort Study. The APNA Study. Eur. Psychiatry 2016, 32, 55-60. https://doi.org/10.1016/j.eurpsy.2015.11.003.

10. Martin-Rodriguez, E.; Guillen-Grima, F.; Martí, A.; Brugos-Larumbe, A. Comorbidity Associated with Obesity in a Large Population: The APNA Study. Obesity Research and Clinical Practice. 2015, pp 435-447. https://doi.org/10.1016/j.orcp.2015.04.003.

11. Santos Palacios, S.; Llavero Valero, M.; Brugos-Larumbe, A.; Díez, J. J.; Guillén-Grima, F.; Galofré, J. C. Prevalence of Thyroid Dysfunction in a Large Southern European Population. Analysis of Modulatory Factors. The APNA Study. Clin. Endocrinol. (Oxf). 2018, 89 (3), 367-375. https://doi.org/10.1111/cen.13764.

12. Real Decreto-Ley 16/2012, de 20 de Abril, de Medidas urgentes para garantizar la sostenibilidad del Sistema Nacional de Salud y mejorar la calidad y seguridad de sus prestaciones. Boletín Oficial del Estado 2012, (98), de 24/04/2012, 31278-31312.

13. Charlson, M. E.; Pompei, P.; Ales, K. L.; MacKenzie, C. R. A New Method of Classifying Prognostic Comorbidity in Longitudinal Studies: Development and Validation. J. Chronic Dis. 1987, 40 (5), 373-383. https://doi.org/10.1016/0021-9681(87)90171-8.

14. Quan, H.; Li, B.; Couris, C. M.; Fushimi, K.; Graham, P.; Hider, P.; Januel, J.-M.; Sundararajan, V. Updating and Validating the Charlson Comorbidity Index and Score for Risk Adjustment in Hospital Discharge Abstracts Using Data from 6 Countries. Am. J. Epidemiol. 2011, 173 (6), 676-682. https://doi.org/10.1093/aje/kwq433. 
15. Dean AG, Sullivan KM, S. M. OpenEpi: Open Source Epidemiologic Statistics for Public Health, Versión 3.01.

16. Abidi, O.; Vercherin, P.; Massoubre, C.; Bois, C. Le Risque Cardiovasculaire Global Des Patients Atteints de Schizophrénie Hospitalisés En Psychiatrie Au CHU de Saint-Étienne. Encephale. 2019, $45 \quad$ (3), $200-206$. https://doi.org/10.1016/j.encep.2018.06.008.

17. Yang, X.; Chen, Y.; Wang, H.; Fu, X.; Kural, K. C.; Cao, H.; Li, Y. Schizophrenia Plays a Negative Role in the Pathological Development of Myocardial Infarction at Multiple Biological Levels. Front. Genet. 2021, 12, 607690. https://doi.org/10.3389/fgene.2021.607690.

18. Corfdir, C.; Pignon, B.; Szöke, A.; Schürhoff, F. [Accelerated Telomere Erosion in Schizophrenia: A Literature Review]. Encephale. 2021, 47 (4), 369-375. https://doi.org/10.1016/j.encep.2020.12.001.

19. Saravane, D.; Feve, B.; Frances, Y.; Corruble, E.; Lancon, C.; Chanson, P.; Maison, P.; Terra, J.-L.; Azorin, J.-M. Élaboration de Recommandations Pour Le Suivi Somatique Des Patients Atteints de Pathologie Mentale Sévère. Encephale. 2009,35 (4), 330-339. https://doi.org/10.1016/j.encep.2008.10.014.

20. Solmi, M.; Fiedorowicz, J.; Poddighe, L.; Delogu, M.; Miola, A.; Høye, A.; Heiberg, I. H.; Stubbs, B.; Smith, L.; Larsson, H.; Attar, R.; Nielsen, R. E.; Cortese, S.; Shin, J. Il; Fusar-Poli, P.; Firth, J.; Yatham, L. N.; Carvalho, A. F.; Castle, D. J.; Seeman, M. V; Correll, C. U. Disparities in Screening and Treatment of Cardiovascular Diseases in Patients With Mental Disorders Across the World: Systematic Review and Meta-Analysis of 47 Observational Studies. Am. J. Psychiatry 2021, appiajp202121010031. https://doi.org/10.1176/appi.ajp.2021.21010031.

21. Kapral, M. K.; Kurdyak, P.; Casaubon, L. K.; Fang, J.; Porter, J.; Sheehan, K. A. Stroke Care and Case Fatality in People with and without Schizophrenia: A Retrospective Cohort Study. BMJ Open 2021, 11 (6), e044766. https://doi.org/10.1136/bmjopen-2020-044766.

22. Lemogne, C.; Blacher, J.; Airagnes, G.; Hoertel, N.; Czernichow, S.; Danchin, N.; Meneton, P.; Limosin, F.; Fiedorowicz, J. G. Management of Cardiovascular Health in People with Severe Mental Disorders. Curr. Cardiol. Rep. 2021,23 (2), 7. https://doi.org/10.1007/s11886-020-01436-5.

23. Lai, F. T. T.; Guthrie, B.; Mercer, S. W.; Smith, D. J.; Yip, B. H. K.; Chung, G. K. K.; Lee, K.-P.; Chung, R. Y.; Chau, P. Y. K.; Wong, E. L. Y.; Yeoh, E.-K.; Wong, S. Y. S. Association between Antipsychotic Use and Acute Ischemic Heart Disease in Women but Not in Men: A Retrospective Cohort Study of over One Million Primary Care Patients. BMC Med. 2020,18 (1), 289. https://doi.org/10.1186/s12916-020-01765-w.

24. Chen, C.-H.; Leu, S.-J. J.; Hsu, C.-P.; Pan, C.-C.; Shyue, S.-K.; Lee, T.-S. Atypical Antipsychotic Drugs Deregulate the Cholesterol Metabolism of Macrophage-Foam Cells by Activating NOX-ROS-PPAR $\gamma$-CD36 Signaling Pathway. Metabolism. 2021, 123, 154847. https://doi.org/10.1016/j.metabol.2021.154847.

25. Santa Cruz, E. C.; Zandonadi, F. da S.; Fontes, W.; Sussulini, A. A Pilot Study Indicating the Dysregulation of the Complement and Coagulation Cascades in Treated Schizophrenia and Bipolar Disorder Patients. Biochim. Biophys. acta. Proteins proteomics 2021, 1869 (8), 140657. https://doi.org/10.1016/j.bbapap.2021.140657.

26. Chan, J. K. N.; Wong, C. S. M.; Or, P. C. F.; Chen, E. Y. H.; Chang, W. C. Diabetes Complication Burden and Patterns and Risk of Mortality in People with Schizophrenia and Diabetes: A Population-Based Cohort Study with 16-Year Follow-Up. Eur. Neuropsychopharmacol. 2021, 53, 79-88. https://doi.org/10.1016/j.euroneuro.2021.08.263.

27. Hjorth, P.; Juel, A.; Hansen, M. V.; Madsen, N. J.; Viuff, A. G.; Munk-Jørgensen, P. Reducing the Risk of Cardiovascular Diseases in Non-Selected Outpatients With Schizophrenia: A 30-Month Program Conducted in a Real-Life Setting. Arch. Psychiatr. Nurs. 2017, 31 (6), 602-609. https://doi.org/10.1016/j.apnu.2017.08.005.

28. Selby, P.; Vojtila, L.; Ashfaq, I.; Dragonetti, R.; Melamed, O. C.; Carriere, R.; LaChance, L.; Kohut, S. A.; Hahn, M.; Mulsant, B. H. Technology-Enabled Collaborative Care for Youth with Early Psychosis: A Protocol for a Feasibility Study to Improve Physical Health Behaviours. Early Interv. Psychiatry 2021, 15 (4), 828-836. https://doi.org/10.1111/eip.13018. 